\title{
Editorial
}

\section{Making conservation work}

T $\mathrm{t}$ is easy to confuse conservation with preservation. The former requires a dynamic approach to reaching Lobjectives, coping with change and recognising that ecosystems are constantly in flux. Preservation is more passive, wanting to keep everything unchanged. Approaches to conservation at the Antarctic Treaty have largely been about preservation and so the last meeting of the Committee for Environmental Protection (CEP) in Edinburgh marked a major turning point. It was finally agreed that the two species of fur seal, Arctocephalus gazella and A. tropicalis, could be delisted from Annex II of the Protocol and would no longer be regarded as Specially Protected Species. A conservation success!

Many readers could be forgiven if they do not know what Antarctic Specially Protected Species are and why this was such a major step forward. Usually conservation issues are about species decline or extinction, so taking away a category of protection might seem unusual.

Back in 1964 when the Agreed Measures for the Conservation of the Antarctic Flora and Fauna were accepted there was concern about the two species of fur seal. These had been hunted almost to extinction in the 19th century and, with only small relictual populations left, it was felt that they should be listed as specially protected to allow them to recover unhindered. There was no scientific process for choosing species for this classification, just a gut feeling amongst the scientists working on seals. What special protection should comprise was also not stipulated, being apparently left to the imagination of Treaty Parties.

This idea of "special protection" was carried across into the Protocol. The species listed under the Agreed Measures (fur seals and the Ross seal) were transferred across, with still no attempt to provide any scientific justification for the choices nor any programme of measures that might help the populations recover. In the last 40 years there had been very big changes in the fur seal populations and in the way this classification was being used elsewhere in the world. At last the CEP woke up to this and asked SCAR to provide an assessment of their likely endangerment using the internationally agreed IUCN criteria. The data were unequivocal - both species are expanding in numbers and range, there are no major risks to them and with population estimates of millions of animals there is clearly no need for any special protection. The meeting agreed to delist the species, despite some misgivings on the part of two countries that this somehow gave the wrong signal to the public. Various concerns were voiced about the impacts of deaths from entanglement in krill nets, by predation by leopard seals and most amazingly, from ASOC, the contention that this delisting would somehow trigger widespread culling of the seals.

Like whales seals can be seen as iconic species, and it then becomes difficult to have a sensible and rational discussion about management, based on scientific data, as emotional arguments keep getting in the way. It was good to see the CEP avoiding going down this path - which has proved disastrous for the International Whaling Commission - and recognising its responsibilities on the basis of the data.

Why is this so important? Because this whole process has brought the ATCM more firmly into contact with the modern conservation philosophy that governs actions in the rest of the world. The Parties have now adopted a set of internationally agreed scientific criteria for endangerment and a process for listing and delisting that makes conservation a dynamic activity.

Fur seal recovery is a great success and should be celebrated by moving interest and resources to those species that are declining and need immediate attention. The decision to delist does that and establishes that species should move on and off the list in Annex II as the risk to them changes. Now we need to get the CEP to see that active management of protected areas is also a possibility if we are to cope with the impacts of climate change.

DAVID WALTON 
https://doi.org/10.1017/S0954102006000332 Published online by Cambridge University Press 